\title{
Plasmacytoid Lymphocytes: A Diagnostic Clue for Dengue Fever
}

\author{
Yasuhiro Tanaka
}

Key words: plasmacytoid lymphocytes, dengue fever, blood smear

(Intern Med 57: 2917, 2018)

(DOI: 10.2169/internalmedicine.0179-17)
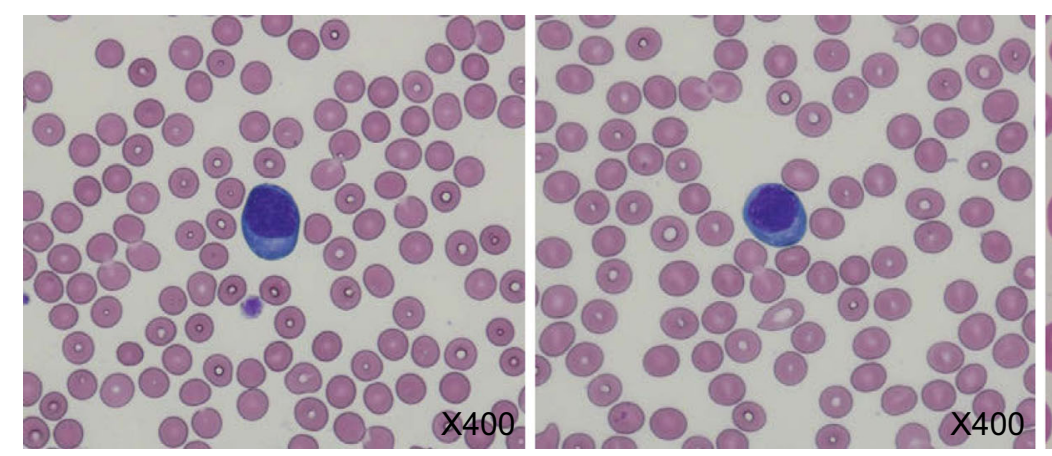

Picture.

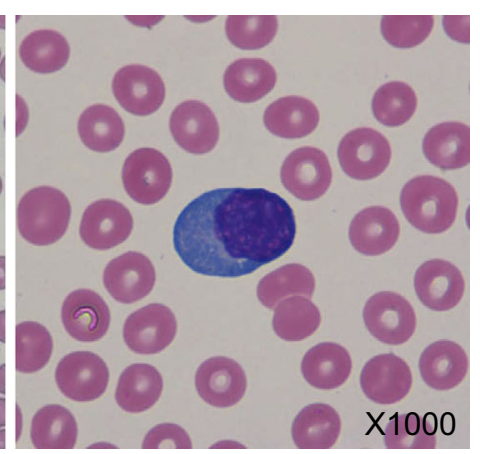

1000
A previously healthy 24-year-old woman presented with a five-day history of high fever and diarrhea. Five days before her admission, she had traveled and worked in India for 20 days, where she was bitten by mosquitoes despite using an insect repellent. Laboratory examinations showed leukopenia, thrombocytopenia, and an abnormal liver function. No pathological organisms were grown on stool or blood cultures. A peripheral blood smear revealed an increased proportion (up to $25 \%$ ) of plasmacytoid lymphocytes (Picture). DENV-1 was detected in her serum, so she was diagnosed with dengue fever. Supportive treatment resulted in the resolution of her symptoms and laboratory abnormalities and the disappearance of plasmacytoid lymphocytes.

Rubella and dengue infection are the only infectious etiologies for plasmacytoid lymphocytosis (1). Blood plasmacytosis was observed in $64 \%$ to $73 \%$ of dengue infections (2). A peripheral blood smear is an easy, low-cost test. We should check peripheral blood smears when returnees from endemic areas of dengue fever show leukopenia and thrombocytopenia.

The author states that he has no Conflict of Interest (COI).

\section{References}

1. Gawoski JM, Ooi WW. Dengue fever mimicking plasma cell leukemia. Arch Pathol Lab Med 127: 1026-1027, 2003.

2. Thai KT, Wismeijer JA, Zumpolle C, de Jong MD, Kersten MJ, de Vries PJ. High incidence of peripheral blood plasmacytosis in patients with dengue virus infection. Clin Microbiol Infect 17: 1823-1828, 2011.

The Internal Medicine is an Open Access article distributed under the Creative Commons Attribution-NonCommercial-NoDerivatives 4.0 International License. To view the details of this license, please visit (https://creativecommons.org/licenses/ by-nc-nd/4.0/).

Department of Hematology and Clinical Immunology, Kobe City Nishi-Kobe Medical Center, Japan Received: September 8, 2017; Accepted: January 29, 2018; Advance Publication by J-STAGE: May 18, 2018 Correspondence to Dr. Yasuhiro Tanaka, yasuhiro_tanaka@kcho.jp

(C) 2018 The Japanese Society of Internal Medicine. Intern Med 57: 2917, 2018 